\title{
Google Earth Pro, Panoramio e Youtube como auxílio ao reconhecimento de knickpoints em afluentes dos rios das Velhas e Paraopeba, em Minas Gerais
}

\author{
Google Earth Pro, Panoramio and YouTube as an aid to recognition of the \\ knickpoints in tributaries of the Velhas and Paraopeba rivers, in Minas Gerais
}

Renata Jordan Henriques
Mestranda em Geografia e Análise Ambiental na
Universidade Federal de Minas Gerais, Brasil
renatajhques@gmail.com

Roberto Célio Valadão

Professor Titular no Departamento de Geografia da

Universidade Federal de Minas Gerais, Brasil

valadao@ufmg.br

\begin{abstract}
Resumo
Os elementos constituintes da rede hidrográfica que compõem a superfície terrestre são fundamentais na investigação da morfogênese e morfodinâmica das formas de relevo. Nesse contexto se destacam as rupturas de declividade - os knickpoints - presentes nos perfis longitudinais dos principais afluentes do trecho centro-sul do divisor hidrográfico entre as bacias dos rios das Velhas e Paraopeba, em Minas Gerais. Na investigação desses knickpoints, objeto de análise neste trabalho, foram empregados na identificação da geometria das rupturas por modelos digitais de elevação, imagens orbitais disponibilizadas no Google Earth Pro, fotografias arquivadas no Panoramio e vídeos compartilhados pela plataforma Youtube. Os resultados indicaram rupturas que geram cachoeiras, corredeiras, além de alguns knickpoints utilizados para a construção de barragens. Esse conjunto de recursos se revelou eficiente na identificação e caracterização de knickpoints em canais fluviais, bem como exerceu papel fundamental no planejamento de trabalhos de campo, conduzidos a posteriori.
\end{abstract}

Palavras-chave: geomorfologia fluvial, geotecnologias, perfil longitudinal fluvial. Abstract

The elements of the hydrographic network that make up the terrestrial surface are fundamental in the investigation of the morphogenesis and morphodynamics of the relief forms. In this context, the slope ruptures - the knickpoints - present in the longitudinal profiles of the main tributaries of the central-south section of the hydrographic divisor between the Velhas and Paraopeba river basins in Minas Gerais. In the investigation of these knickpoints, object of analysis in this work, were used to identify the geometry of the ruptures by digital elevation models, orbital images available in Google Earth Pro, photographs archived in the Panoramio and videos shared by the Youtube platform. The results indicate ruptures that generate waterfalls, stretches of fast flow, and some knickpoints used for dam construction. This set of resources proved efficient in the identification and characterization of knickpoints in fluvial channels, as well as played a fundamental role in the planning of fieldwork, conducted in the future.

Keywords: fluvial geomorphology, geotechnologies, longitudinal river profile. 


\section{INTRODUÇÃO}

A investigação da rede hidrográfica que compõe e modela a superfície terrestre desempenha papel fundamental na compreensão da morfogênese e morfodinâmica das formas de relevo. Vários são os indicadores utilizados para se investigar o comportamento hidrológico de um dado curso fluvial, os quais se processam em múltiplas escalas espaço-temporais, tais como os parâmetros de geometria espacial, as compartimentações topográficas regionais de bacias hidrográficas e as mensurações da carga sedimentar em trânsito nos canais (SCHUMM; LICHTY, 1965; CHARLTON, 2008).

A geometria espacial dos cursos d'água segundo as perspectivas cartográficas em planta e em perfil constitui um dos principais recursos empregados na análise dos comportamentos hidrodinâmico e genético da rede fluvial (CARLSTON, 1969; HARTVICH, 2005). Em razão desse fato, desde meados dos anos de 1950 e 1960 a geometria fluvial tem sido investigada por meio da elaboração de perfis longitudinais, sendo a identificação de knickpoints um importante indicador do balanço erosão/deposição e da distribuição de energia no sistema fluvial (RÃDOANE et al., 2003).

Por meio de sistemático avanço tecnológico alcançado, sobretudo, a partir da década de 1980, as investigações da rede hidrográfica passaram a ser realizadas também a partir do suporte de softwares de análise espacial, a exemplo do Spring, ArcGIS, Quantum GIS e ENVI, o que possibilitou o tratamento matemático das múltiplas facetas da superfície terrestre e de suas variadas geometrias (GRIFFITHS et al., 2011; FERREIRA et al., 2012). Outras plataformas de compartilhamento digital, mesmo que não necessariamente associadas as geoinformações, foram também desenvolvidas e aprimoradas, dentre elas o Google Earth Pro que disponibiliza compilados de imagens orbitais, o Panoramio que compreende fotografias fornecidas por usuários do Google Earth Pro, até mesmo o Youtube, em que usuários compartilham vídeos de natureza diversificada.

É neste contexto que se insere este trabalho, cujo objetivo é investigar como esses recursos tecnológicos contemporâneos podem subsidiar a identificação e análise das principais rupturas de declive presentes na geometria do perfil longitudinal de canais fluviais, rupturas essas denominadas knickpoints. Para isso foram selecionados os principais afluentes de até $4^{\text {a }}$ ordem, segundo metodologia de Strahler (1957), que integram o trecho centro-sul do divisor hidrográfico entre as bacias do rio das Velhas e Paraopeba, em Minas Gerais (Figura 1). Esta área se insere no contexto geológico de transição entre a bacia sedimentar neoproterozoica do Grupo Bambuí e o Complexo Belo Horizonte, esse último composto por rochas gnáissico-graníticas do Arqueano (HASUI, 2012). O modelado do relevo, por sua vez, possui relativa correspondência a essa variabilidade geológica, cuja topografia se torna mais regular e plana à medida que se adentra no domínio geológico das rochas sedimentares, ao norte da área investigada. 


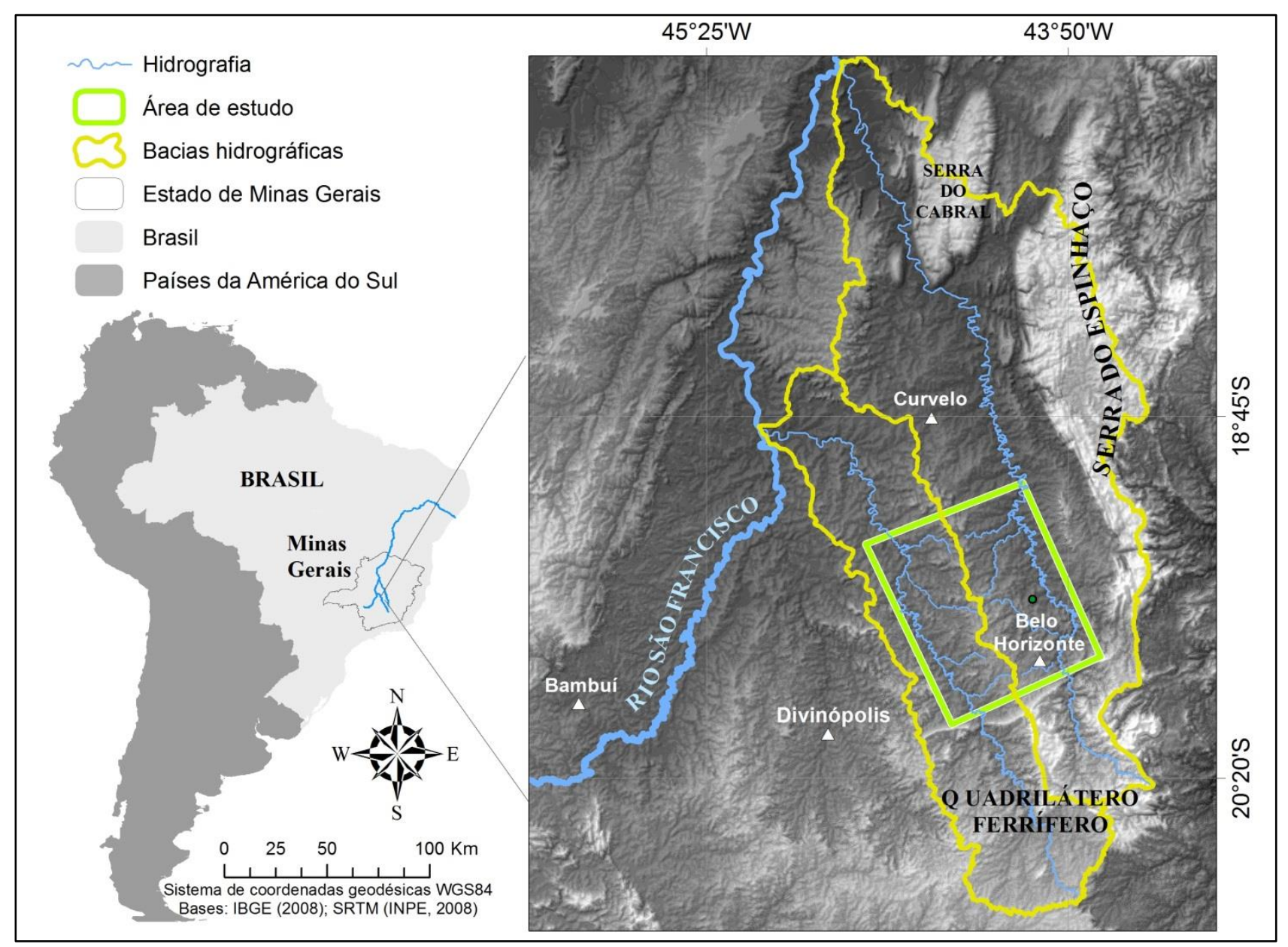

Figura 1 - Localização dos principais afluentes dos rios das Velhas e Paraopeba investigados neste trabalho. Fonte: Organizado pelos autores, a partir de bases do INPE (2008) e IBGE (2008).

O presente trabalho trata do reconhecimento das condições espaciais de knickpoints em canais fluviais, cujos procedimentos empregados se revelaram efetivos no planejamento e desenvolvimento de trabalho de campo a posteriori. Nos procedimentos executados durante este trabalho se revelou fundamental o uso de Modelo Digital de Elevação SRTM (INPE, 2008), da base cartográfica da hidrografia em escala 1:50.000 (IBGE, 2008), de imagens orbitais disponibilizadas pelo programa Google Earth Pro, de fotografias da plataforma Panoramio e de registros em vídeos no Youtube.

\section{FUNDAMENTAÇÃO TEÓRICA}

No âmbito das investigações geomorfológicas a rede hidrográfica constitui um dos componentes fundamentais na esculturação das formas de relevo. Há distintos modelos conceituais que tratam da morfodinâmica e morfogênese da superfície terrestre em que as condições hidrodinâmicas atuam em múltiplas escalas espaço-temporais. Uma das maneiras de se investigar esses fenômenos que se processam na superfície terrestre e a esculturam se faz mediante emprego do recorte espacial de bacias hidrográficas, ou seja, o conjunto integrado pela rede de canais 
fluviais, interflúvios, talvegues e a geometria das vertentes. Neste aspecto, uma bacia hidrográfica poderia ainda ser compartimentada em três principais unidades, cujos processos operam de diferentes maneiras (Figura 2).

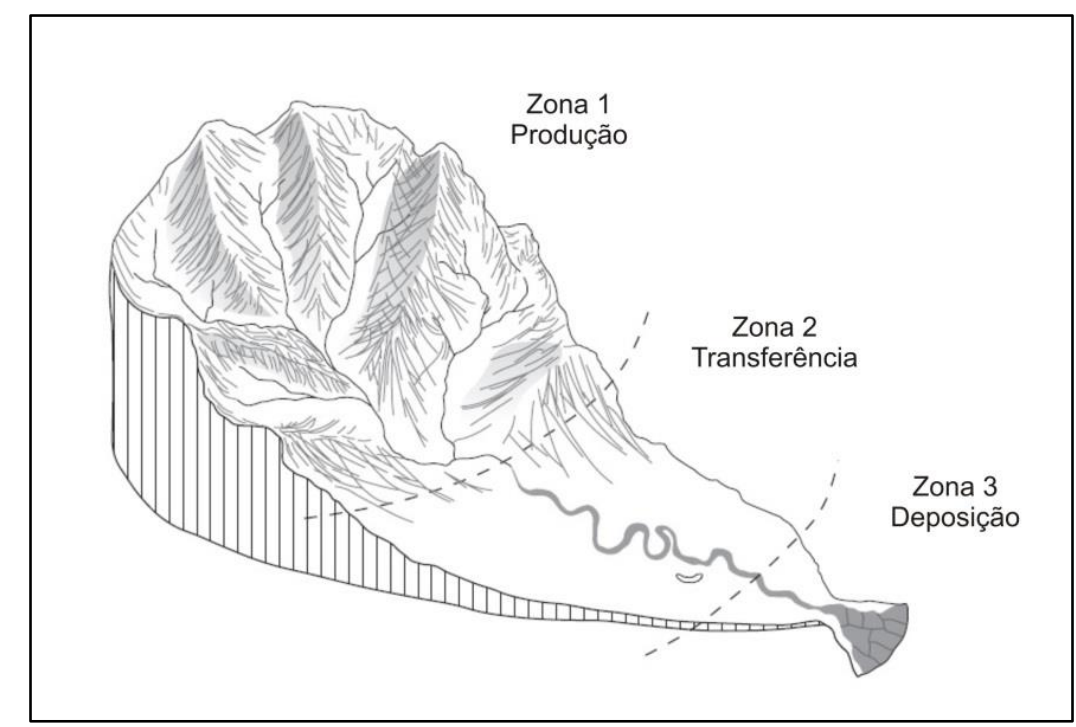

Figura 2 - Compartimentação de uma bacia hidrográfica hipotética segundo comportamento geomorfohidrológico, proposta por Charlton (2008). Fonte: Adaptado de Charlton (2008).

Segundo a proposta de Charlton (2008), na Zona 1 prevalecem a maior energia na dinâmica hidrossedimentológica e, consequentemente, a maior incisão vertical dos cursos fluviais, onde também é maior a declividade. Esta zona representa a porção da bacia em que o recuo erosivo remontante ocorre de maneira mais intensa em relação aos trechos de jusante. Seus canais fluviais são aqueles de $1^{\mathrm{a}}$ a $3^{\mathrm{a}}$ ordens. Em contrapartida, a Zona 3, referente à foz de uma bacia, corresponde a área de maior recepção e deposição dos materiais transportados provenientes de montante. Já a Zona 2, por sua vez, representa ambiente intermediário em que ocorre a mescla do resultado dos processos atuantes à montante nas cabeceiras e à jusante da foz (CHARLTON, 2008), cuja hierarquia fluvial é comumente composta por afluentes de $4^{\mathrm{a}}$ a $6^{\mathrm{a}}$ ordens.

Tomando-se uma bacia hidrográfica como recorte espacial, ao se traçar um perfil longitudinal do canal fluvial principal é possível identificar sua organização geométrica que, em certa medida, reflete a variabilidade processual e morfológica das zonalidades 1,2 e 3 de Charlton (2008). Um perfil longitudinal nada mais é que a representação bidimensional de um canal fluvial lótico, capaz de revelar características e alguns atributos, tais como altimetria, extensão e morfologia da concavidade do canal (Figura 3). Esse perfil plotado em gráfico se traduz, geralmente, em uma curvatura logarítmica linear negativa que, em um modelo ideal, corresponde a um estágio de relativa condição de equilíbrio, ou quase-equilibrium, no balanço 
erosão/sedimentação e na distribuição de energia ao longo da seção (SCHUMM; LICHTY, 1965; RÃDOANE et al., 2003; SELANDER, 2004).

Sendo a superfície terrestre o resultado de um conjunto de interações entre componentes endógenos (arcabouço geológico e mobilidade tectônica) e exógenos (sobretudo condições atmosféricas, hidrológicas e colonizações biológicas), os canais fluviais podem ser relativamente sensíveis a quaisquer perturbações ambientais capazes de alterar níveis de base que condicionam a morfodinâmica e morfogênese superficial. Nesse contexto, a geometria de um perfil longitudinal pode indicar como esses vários componentes endógenos e exógenos se interagem no tempo e espaço. Em razão disso, a identificação de uma ruptura abrupta na declividade ao longo da curvatura do perfil longitudinal é considerada na literatura especializada uma evidência de anomalia hidrológica (SKLAR; DIETRICH, 1998; RÃDOANE et al., 2003; SELANDER, 2004) (Figura 3).

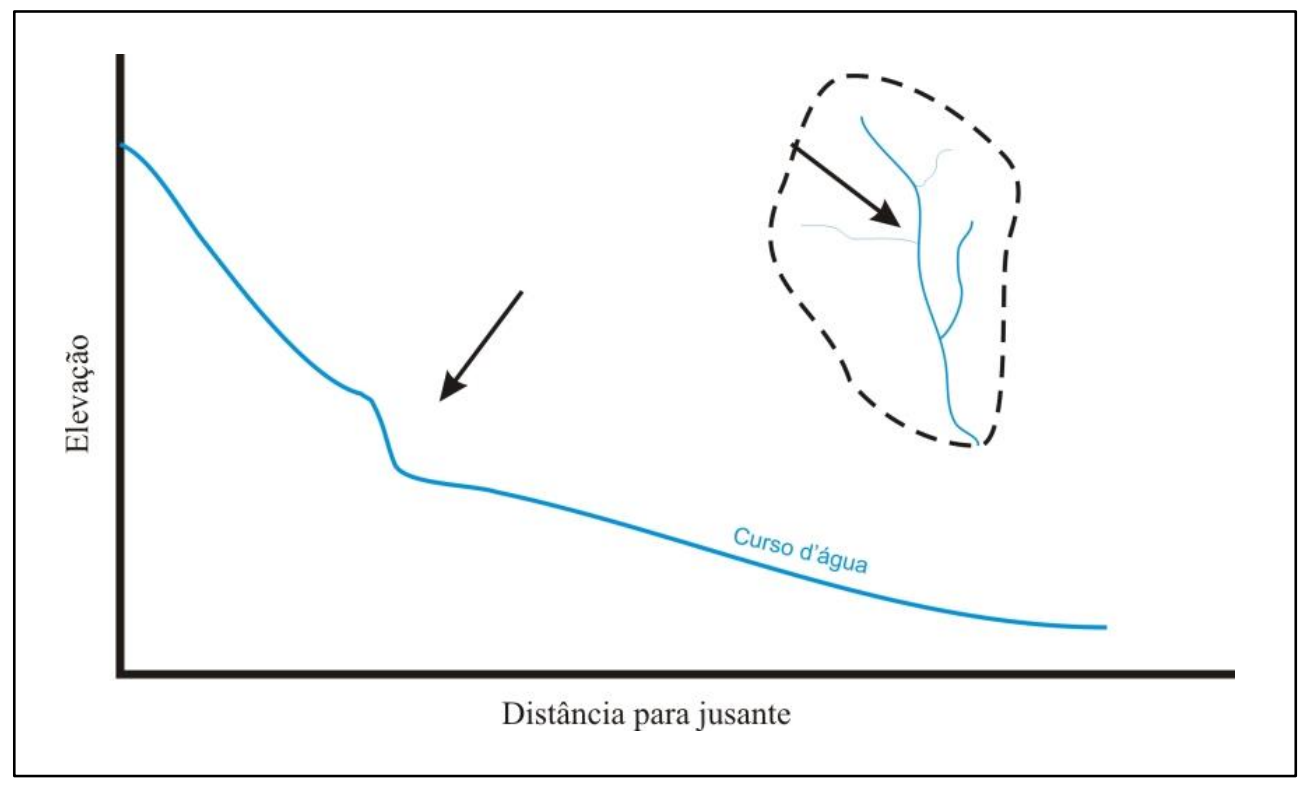

Figura 3 - Representação esquemática de um perfil longitudinal e seu respectivo knickpoint. Fonte: Organizado pelos autores.

Segundo Rãdoane et al. (2003), investigar um curso fluvial sob a perspectiva em perfil remonta discussões que se sucederam na história, notadamente nas décadas de 1950 e 1960. Após a década de 1990, por sua vez, as discussões foram reavivadas mediante introdução de novos instrumentos e procedimentos de análise. Na literatura é recorrente a associação entre a morfologia dos perfis e o balanço entre sedimentação e erosão hidrológica, de tal modo que caso um perfil revele condições de relativo equilíbrio - graded profile -, é ele prontamente associado ao estágio de maturidade. Esta aproximação se fundamenta nos principais modelos regionais de evolução do relevo, a exemplo daquele proposto por Davis (1899), cujo estágio de maturidade de um curso fluvial é progressivamente atingido de jusante para montante por meio da sua evolução remontante, a qual conduz à relativa estabilidade entre erosão, sedimentação e maior homogeneidade na 
distribuição de energia no sistema fluvial. Todavia, no trabalho aqui desenvolvido, parte-se do princípio de que a geometria de um curso fluvial pode estar associada tanto a perturbações ambientais capazes de reorganizar a rede hidrográfica, quanto a aspectos condicionados, por exemplo, à variabilidade e organização estrutural do arcabouço geológico.

Do ponto de vista dos atuais recursos tecnológicos que disponibilizam dados sobre a superfície terrestre encontram-se o Google Earth Pro, o Panoramio e o Youtube. O primeiro é um programa desenvolvido em 2004 pela Keyhole, Inc. e posteriormente adquirido pela empresa Google em 2005, cujo nome passou a ser Google Earth. A principal função deste programa é disponibilizar representações tridimensionais da superfície terrestre, além de possuir um compilado de imagens orbitais geradas por variados satélites e várias temporalidades. Em meados de 2015, por sua vez, foi disponibilizado gratuitamente o Google Earth Pro, o qual passou a oferecer maiores recursos para se explorar virtualmente a superfície terrestre. O Panoramio, lançado em 2014 e também pertencente a Google, disponibiliza uma plataforma virtual cujos usuários podem compartilhar registros de fotografias. Já o Youtube, também adquirido pela Google, foi desenvolvido em 2005 e sua função é servir como plataforma de compartilhamento de vídeos digitais postados por seus usuários.

\section{PROCEDIMENTOS METODOLÓGICOS}

Para a execução deste trabalho foram realizadas as seguintes etapas metodológicas: (i) delimitação das bacias hidrográficas dos principais afluentes que compõem o divisor entre os rios das Velhas e Paraopeba; (ii) hierarquização da rede fluvial de cada bacia; (iii) confecção de perfis longitudinais; (iv) identificação dos principais pontos de rupturas - knickpoints -, presentes ao longo desses perfis; (v) aquisição de imagens de satélite disponibilizadas pelo Google Earth Pro; (vi) aquisição de fotografias e vídeos que retratam os knickpoints mediante consulta às plataformas

\section{Panoramio e Youtube.}

As bacias hidrográficas foram delimitadas manualmente no ArcGIS 10.1 a partir das curvas de nível e da hidrografia, em escala 1:50.000, do Projeto Geominas (IBGE, 2008). A hierarquização da rede hidrográfica foi baseada na metodologia de Strahler (1957), sendo os canais de primeira ordem equivalentes às cabeceiras de drenagem e geralmente efêmeros. Este procedimento, por se aplicar à escala das bacias hidrográficas investigadas, permite sua associação com as zonas propostas por Charlton (2008). Essa hierarquização foi realizada a partir da confluência de dois segmentos fluviais, cuja hierarquia é aumentada à medida em que dois afluentes de mesma ordem se encontram (Figura 4). 


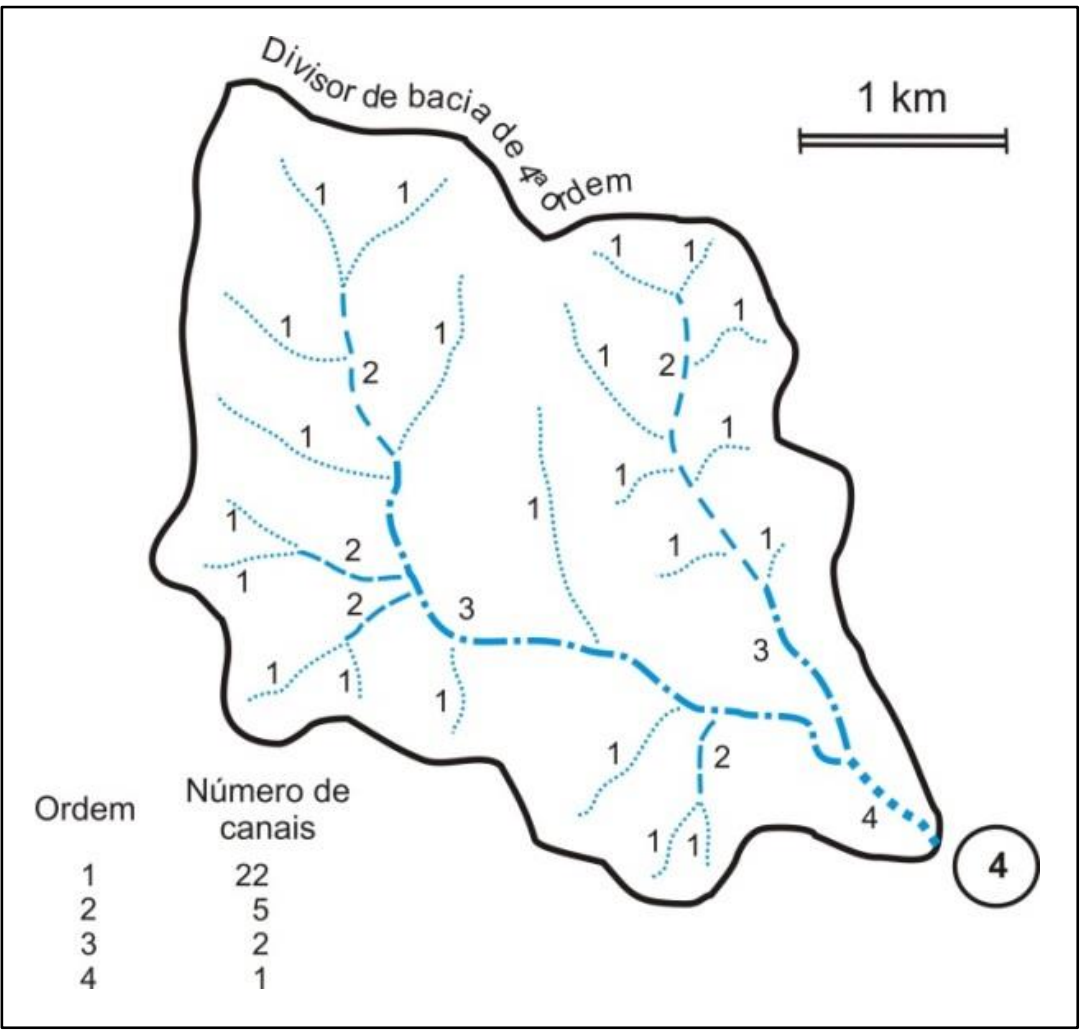

Figura 4 - Metodologia de hierarquização de ordem de canais.

Fonte: Adaptado de Strahler (1957).

Para a confecção dos perfis longitudinais foram empregados os programas ArcGIS 10.1, Excel 2010 e CorelDRAW X3. No ArcGIS 10.1 foi tratada a base cartográfica de hidrografia sobre o modelo digital de elevação (MDE) SRTM do Projeto Topodata (INPE, 2008). Em razão da compatibilidade entre as bases vetorial e matricial, o traçado do perfil longitudinal foi adaptado visando a redução da interferência dos valores dos pixels. O traçado, neste contexto, segue os contornos de reentrâncias a partir de curvas de nível equidistantes de $12 \mathrm{~m}$, extraídas para vetores a partir do MDE SRTM (Figura 5). O dado matricial SRTM do projeto Topodata possui resolução espacial de 30m, cujas curvas de nível equidistantes em 12m equivalem à escala 1:70.000. Por meio da ferramenta $3 D$ Analyst do ArcGIS 10.1 foi utilizada a linha de interpolação (interpolate line) para definir o traçado do canal sobre o MDE.

Uma vez traçada a linha do canal foi gerado o gráfico do perfil longitudinal pelo profile graph. Os valores para o eixo X (distância longitudinal) e Y (altimetria) foram exportados para o Excel 2010 em extensão .xsl, sendo estes normalizados em 100\% para efeitos de comparação entre os afluentes, como proposto por Corseuil (2006). A partir da morfologia dos perfis plotadas em gráfico e dos perfis normalizados no Excel, para ser reconhecido como ruptura estipulou-se o valor mínimo de $12 \mathrm{~m}$ de altitude em uma extensão longitudinal inferir a $300 \mathrm{~m}$ associado a declividades mínimas de $5^{\circ}$. Este intervalo foi definido de acordo com as limitações de reconhecimento e compatibilidade entre os dados vetoriais e matriciais. Optou-se por não utilizar o índice de Hack, 
uma maneira relativamente automatizada de se extrair knickpoints em perfis longitudinais, em virtude da necessidade de se estabelecer as amplitudes de rupturas adequadas à escala dos dados, bem como pela necessidade de reconhecimento das rupturas e seus respectivos reflexos percebidos por demais registros de imagens.
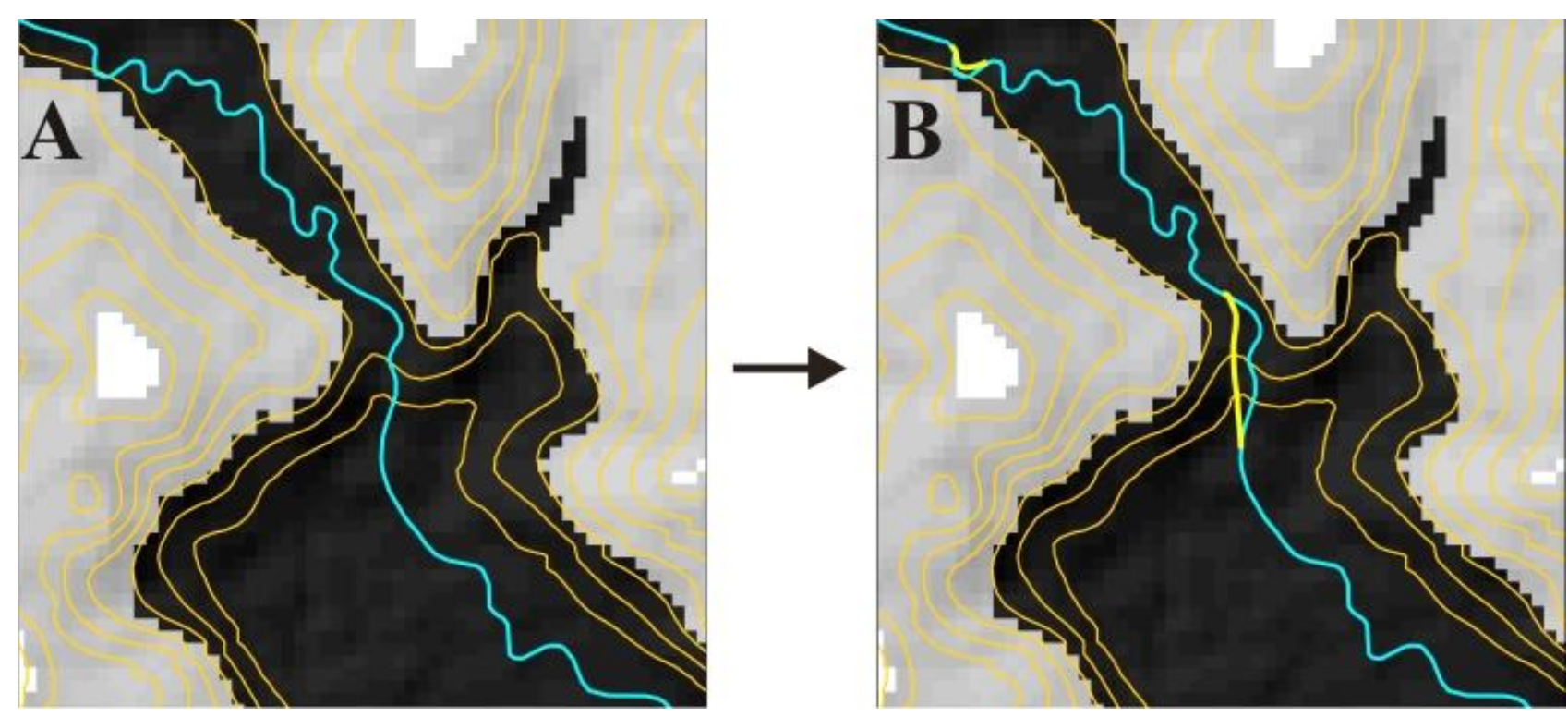

Figura 5 - Ajuste entre as bases matricial e vetorial para extração do perfil longitudinal. Em A, a linha azul corresponde à base hidrográfica vetorial, ao passo que em $\mathbf{B}$ o traçado foi adaptado para coincidir com o talvegue matricial.

Fonte: Organizado pelos autores, a partir das bases do INPE (2008) e IBGE (2008).

Pelo fato do reconhecimento dos knickpoints ter sido efetivado na escala 1:50.000, as rupturas nas declividades dos perfis possivelmente podem ser reconhecidas por meio de imagens orbitais e demais recursos audiovisuais. Uma vez que a amplitude desses knickpoints pode ocasionalmente compreender trechos encachoeirados dos canais fluviais, optou-se por confirmar as rupturas por meio da interpretação de imagens orbitais Landsat/copernicus e DigitalGlobe disponibilizadas no programa Google Earth Pro, pela análise de fotografias na plataforma Panoramio e por registros em vídeo na plataforma Youtube.

\section{RESULTADOS}

Os principais afluentes da margem esquerda do rio das Velhas e os da margem direita do rio Paraopeba investigados neste trabalho apresentam um total de nove knickpoints, cuja localização é mostrada na Figura 6. Estes knickpoints estão concentrados sobretudo naqueles afluentes localizados na porção centro-sul da área investigada, de tal modo que seu maior quantitativo ocorre nos afluentes do rio Paraopeba. As bacias hidrográficas que apresentam maior dimensão são as dos ribeirões da Mata, Jequitibá, dos Macacos e das Abóboras, sendo as menores a do rio Betim e dos 
ribeirões Onça, Cedro e das Tabocas. Os canais fluviais principais que drenam estas bacias têm seus fluxos dirigidos para Leste ou Oeste, embora os rios em que deságuam - rios das Velhas e Paraopeba - apresentem orientação geral Norte-Sul. Ao que tudo indica, esta organização espacial da rede hidrográfica está associada à variabilidade de condicionantes litoestruturais presentes em dois domínios geológicos, um complexo cristalino arqueano e uma bacia sedimentar neoproterozoica.

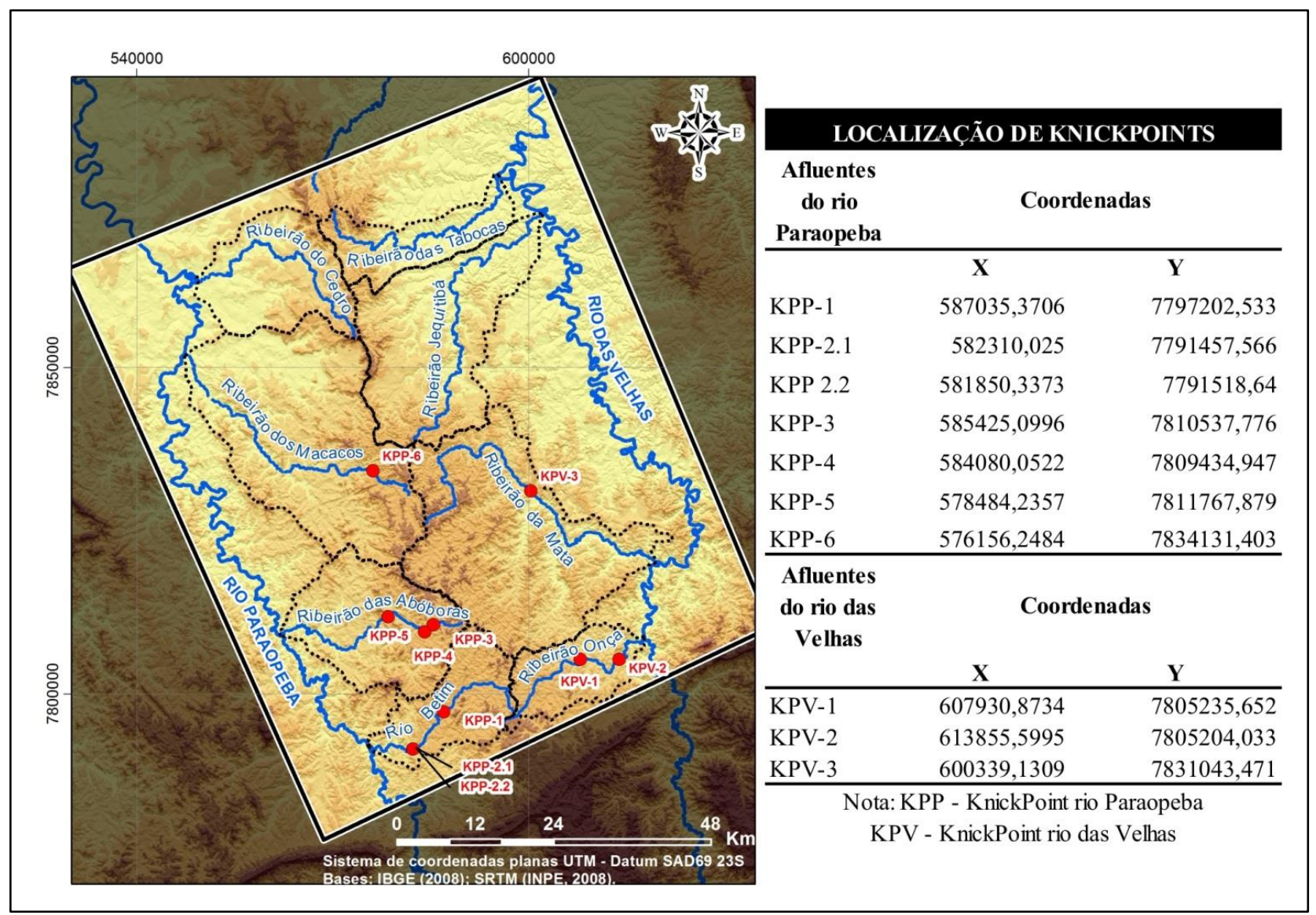

Figura 6 - Distribuição espacial e localização dos knickpoints identificados nos afluentes dos rios das Velhas e Paraopeba e organização geral da rede hidrográfica.

Fonte: Organizado pelos autores, a partir das bases do INPE (2008) e IBGE (2008).

Em relação aos aspectos morfométricos, a rede hidrográfica que compõe as bacias hidrográficas desses afluentes varia entre $2^{\mathrm{a}}$ e $4^{\mathrm{a}}$ ordem, sendo de $2^{\mathrm{a}}$ ordem o ribeirão Onça, $3^{\mathrm{a}}$ o rio Betim e o ribeirão das Tabocas, enquanto os demais são hierarquizados em $4^{\mathrm{a}}$ ordem (Quadro 1). Quanto a este aspecto é importante ressaltar que, no caso do ribeirão Onça e do rio Betim, o intenso processo de urbanização pode ter obliterado e transformado parcialmente sua rede hidrográfica de modificações antrópicas nos leitos dos canais fluviais originais. Todas as bacias hidrográficas analisadas pode ter sua rede hidrográfica associada à zonalidade proposta por Charlton (2008). Há, contudo, uma mescla e flutuabilidade de escalas espaciais envolvidas na delimitação destas zonas, visto que cada bacia possui em si mesma as zonas 1,2 e 3, as quais se estendem das cabeceiras até 
sua foz, ao passo que regionalmente essas bacias podem corresponder às zonas 1 ou 2 caso se considere a dimensão total das bacias dos rios das Velhas ou Paraopeba.

Quadro 1 - Aspectos morfométricos das bacias hidrográficas investigadas, com destaque para seus respectivos perfis longitudinais e knickpoints.

\begin{tabular}{|c|c|c|c|c|c|c|c|c|c|c|c|c|c|c|c|}
\hline \multirow{3}{*}{\multicolumn{2}{|c|}{ Curso fluvial }} & \multicolumn{6}{|c|}{ Knickpoint (KP) } & \multicolumn{2}{|c|}{ Bacia hidrográfica } & \multicolumn{6}{|c|}{ Perfil longitudinal } \\
\hline & & \multirow[b]{2}{*}{ Código } & \multirow{2}{*}{$\begin{array}{c}\text { Dmin } \\
(\mathrm{m})\end{array}$} & \multirow{2}{*}{$\begin{array}{c}\operatorname{Dmax} \\
(\mathbf{m})\end{array}$} & \multirow[b]{2}{*}{ Dint (m) } & \multirow[b]{2}{*}{ DECmax } & \multirow[b]{2}{*}{ DECmédia } & \multirow{2}{*}{$\begin{array}{l}\text { Área } \\
\left(\mathbf{k m}^{2}\right)\end{array}$} & \multirow[b]{2}{*}{ Ordem } & \multirow{2}{*}{$\begin{array}{l}\text { Extensão } \\
\text { total (m) }\end{array}$} & \multirow{2}{*}{$\begin{array}{c}\text { Altitude } \\
\text { Máxima } \\
\text { (m) }\end{array}$} & \multirow{2}{*}{$\begin{array}{c}\text { Altitude } \\
\text { Mínima } \\
\text { (m) }\end{array}$} & \multirow{2}{*}{$\begin{array}{c}\text { Variação } \\
\text { altimétric } \\
\mathbf{a}(\mathbf{m})\end{array}$} & \multicolumn{2}{|c|}{ Coeficiente de } \\
\hline & & & & & & & & & & & & & & $\begin{array}{c}\text { Logarítmo } \\
\text { base (e) }\end{array}$ & Exponencial \\
\hline \multirow{4}{*}{$\begin{array}{c}\text { Rio } \\
\text { Paraopeba } \\
\text { (P) }\end{array}$} & Rio Betim & $\begin{array}{c}\text { KPP-1 } \\
\text { KPP-2.1 } \\
\text { KPP-2.2 }\end{array}$ & $\begin{array}{l}56 \\
66 \\
62 \\
\end{array}$ & $\begin{array}{l}135 \\
232 \\
174\end{array}$ & $\frac{-}{292}$ & $\begin{array}{c}13,89^{\circ} \\
10,94 \\
13,34^{\circ}\end{array}$ & $\begin{array}{l}9,39^{\circ} \\
6,28^{\circ} \\
7,98^{\circ}\end{array}$ & 249,22 & $3^{\mathrm{a}}$ & 35.128 & 927 & 710 & 214 & 0,6279 & 0,8860 \\
\hline & Ribeirão das Abóboras & \begin{tabular}{l|} 
KPP-3 \\
KPP-4 \\
KPP-5
\end{tabular} & $\begin{array}{c}63 \\
55 \\
276\end{array}$ & $\begin{array}{c}63 \\
55 \\
276\end{array}$ & $\begin{array}{l}- \\
- \\
-\end{array}$ & $\begin{array}{l}10,34^{\circ} \\
12,36^{\circ} \\
4,68^{\circ}\end{array}$ & $\begin{array}{c}8,81^{\circ} \\
10,49^{\circ} \\
3,76^{\circ}\end{array}$ & 403,20 & $4^{a}$ & 41.270 & 959 & 697 & 292 & 0,8917 & 0,8947 \\
\hline & Ribeirão dos Macacos & KPP-6 & 68 & 418 & - & $11,58^{\circ}$ & $5,98^{\circ}$ & 844,98 & $4^{\mathrm{a}}$ & 62.677 & 1.023 & 662 & 361 & 0,9138 & 0,9157 \\
\hline & Ribeirão do Cedro & - & - & - & - & - & - & 335,62 & $4^{a}$ & 44.103 & 1.003 & 657 & 346 & 0,9857 & 0,8512 \\
\hline \multirow{4}{*}{$\begin{array}{c}\text { Rio das } \\
\text { Velhas (V) }\end{array}$} & Ribeirão Onça & $\begin{array}{l}\text { KPV-1 } \\
\text { KPV-2 }\end{array}$ & $\begin{array}{l}89 \\
27 \\
\end{array}$ & $\begin{array}{l}89 \\
27\end{array}$ & - & $\begin{array}{c}7,81^{\circ} \\
20,15^{\circ}\end{array}$ & $\begin{array}{c}6,56 \\
12,82^{\circ}\end{array}$ & 196,54 & $2^{\mathrm{a}}$ & 33.861 & 943 & 678 & 265 & 0,8053 & 0,9241 \\
\hline & Ribeirão da Mata & KPV-3 & 106 & 106 & - & $7,52^{\circ}$ & $6,40^{\circ}$ & 809,25 & $4^{\mathrm{a}}$ & 66.660 & 983 & 665 & 318 & 0,9160 & 0,9447 \\
\hline & Ribeirão Jequitibá & - & - & - & - & - & - & 575,18 & $4^{\mathrm{a}}$ & 58.879 & 935 & 608 & 327 & 0,9654 & 0,8711 \\
\hline & Ribeirão das Tabocas & - & - & - & - & - & - & 217,63 & $3^{\mathrm{a}}$ & 48.473 & 951 & 600 & 351 & 0,9747 & 0,8672 \\
\hline & & & Projeto & $\begin{array}{l}\text { se: Moc } \\
\text { spodata }\end{array}$ & $\begin{array}{l}\text { elo digital d } \\
\text { Resolução }\end{array}$ & $\begin{array}{l}\text { le elevação } \\
\text { espacial de }\end{array}$ & $\begin{array}{l}\text { RTM } \\
30 \mathrm{~m} \text { (INPE }\end{array}$ & 2008) & $\begin{array}{c}\text { Strahler } \\
(1957)\end{array}$ & & & & & \multicolumn{2}{|c|}{ Nota: e $\left(n^{\circ}\right.$ Euler $)=2,7182 i$} \\
\hline
\end{tabular}

Abreviações:

Dmin (m) - Distância mínima (metros) entre o intervalo de cotas equidistantes de $12 \mathrm{~m}$

Dmáx (m) - Distância máxima (metros) que enquadra a ruptura como knickpoint

Dint (m) - Em caso de proximidade (knickzone) distância em metros entre knickpoints

DECmax - Declividade máxima (graus) do knickpoint

DECmédia - Declividade média (graus) do trecho que forma o knickpoint

Fonte: Organizado pelos autores.

No que se refere aos afluentes do rio Paraopeba, ao sul da área investigada se encontra o rio Betim, um curso fluvial de $3^{\mathrm{a}}$ ordem cuja bacia hidrográfica drena área de $249 \mathrm{~km}^{2}$. A rede hidrográfica que integra esta bacia possui 27 segmentos de canais, dentre os quais são numerosos os de $1^{\mathrm{a}}$ ordem (22) quando comparados àqueles de $2^{\mathrm{a}}$ ordem (4) (Figura 7). O perfil longitudinal do rio Betim se estende por $35.128 \mathrm{~m}$ e sua amplitude altimétrica é de $214 \mathrm{~m}$, variando entre as cotas topográficas de $927 \mathrm{~m}$ e $710 \mathrm{~m}$. De montante para jusante o primeiro knickpoint (KPP-1) possui declividade média de 9,39 ao longo de uma extensão longitudinal de 135m (Quadro 1), ao passo que sua maior declividade é expressa por até $13,49^{\circ} \mathrm{em}$ uma variação longitudinal de $56 \mathrm{~m}$ entre cotas equidistantes de $12 \mathrm{~m}$.

Em 1972 foi construído no KPP-1 o barramento de Várzea das Flores pela Companhia Mineira de Águas e Esgotos (COPASA), no município de Betim. Este barramento se destina ao abastecimento hídrico dos municípios de Contagem, Betim e Belo Horizonte (SANTOS, 2012). Atualmente este reservatório é destinado a usos múltiplos além do abastecimento, a exemplo da recreação, irrigação e do controle de cheias. A lâmina d'água do reservatório, por sua vez, pode ser observada em imagens orbitais no Google Earth Pro (Figura 7) e em fotografias no Panoramio. 


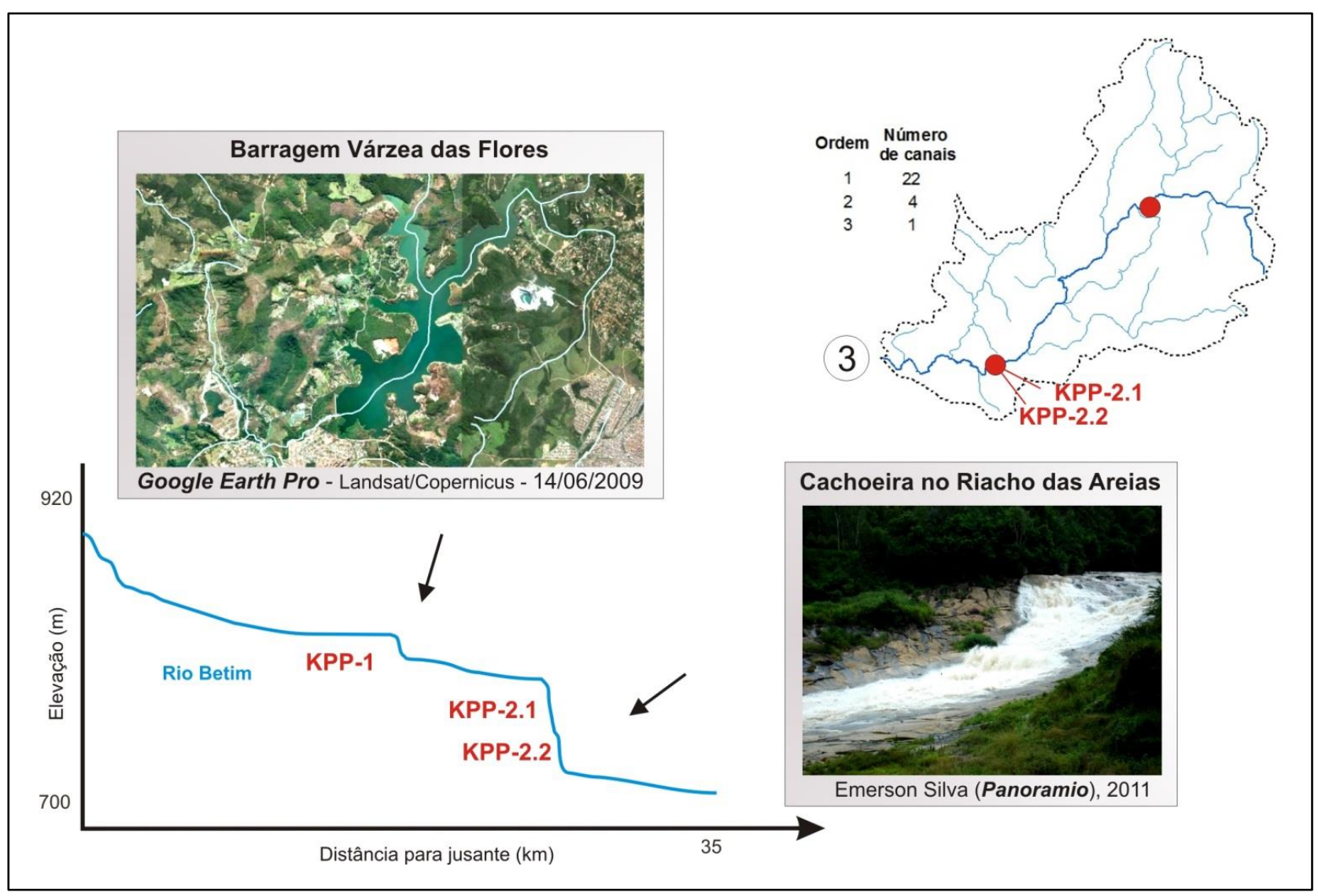

Figura 7 - Perfil longitudinal do rio Betim e seus respectivos knickpoints.

Fonte: Organizado pelos autores.

Enquanto no KPP-1 se registra um barramento, os knickpoints posicionados à jusante dele (KPP-2.1 e KPP-2.2) estão em leito natural e resultam em sequências de trechos encachoeirados (Figura 7). Localmente esse trecho pode ser dividido em dois knickpoints, estando um a $292 \mathrm{~m}$ de distância em relação ao outro, porém, na escala analisada neste trabalho é possível caracterizá-los como knickzone. O KPP-2.1 possui declividade média de $6,28^{\circ}$ ao longo de $232 \mathrm{~m}$, sendo sua declividade máxima de 10,94 em até 66m de extensão; já no KPP-2.2 a declividade média é de $7,98^{\circ}$ em $174 \mathrm{~m}$ longitudinais, cuja declividade máxima é de $13,34^{\circ}$ ao longo de $62 \mathrm{~m}$. Esses knickpoints, na condição de knickzone, formam uma ruptura altimétrica maior e mais alongada e geram cachoeiras próximas da confluência do rio Paraopeba. A plataforma de disponibilização de fotos Panoramio possui registros dessa knickzone, dada sua expressividade em superfície.

O ribeirão das Abóboras constitui curso fluvial com 41.270m de extensão e amplitude altimétrica de $292 \mathrm{~m}$ (Figura 6). Este ribeirão integra uma bacia hidrográfica de $4^{\mathrm{a}}$ ordem que drena $403 \mathrm{~km}^{2}$, além de possui 35 canais de $1^{\mathrm{a}}$ ordem, 10 de $2^{\mathrm{a}}$ ordem e 3 de $3^{\mathrm{a}}$ ordem. Neste ribeirão foram encontrados três knickpoints, sendo a morfologia do perfil relativamente serrilhado, o que faz com que caso os limites aqui empregados na definição de knickpoint fossem menores, ainda seriam registrados um maior número de rupturas. Esta marcante irregularidade morfológica de seu perfil 
resulta em rupturas com relativas similaridades em seus aspectos superficiais (KPP-3, KPP-4 e KPP-5). O KPP-3 possui declividade máxima de 10,34º em uma extensão de $63 \mathrm{~m}$; já o KPP-4 chega a $12,36^{\circ}$ ao longo de $55 \mathrm{~m}$, ao passo que KPP-5 possui declividade máxima de $4,68^{\circ}$ em uma extensão de $275 \mathrm{~m}$ (Quadro 1). Este último se localiza na porção mediana da bacia do ribeirão das Abóboras e, ainda que sua morfometria possua valores menores que KPP-3 e KPP-4, seu comportamento é relativamente semelhante por apresentar sucessão de trechos de corredeira percebíveis em imagens orbitais (Figura 8).

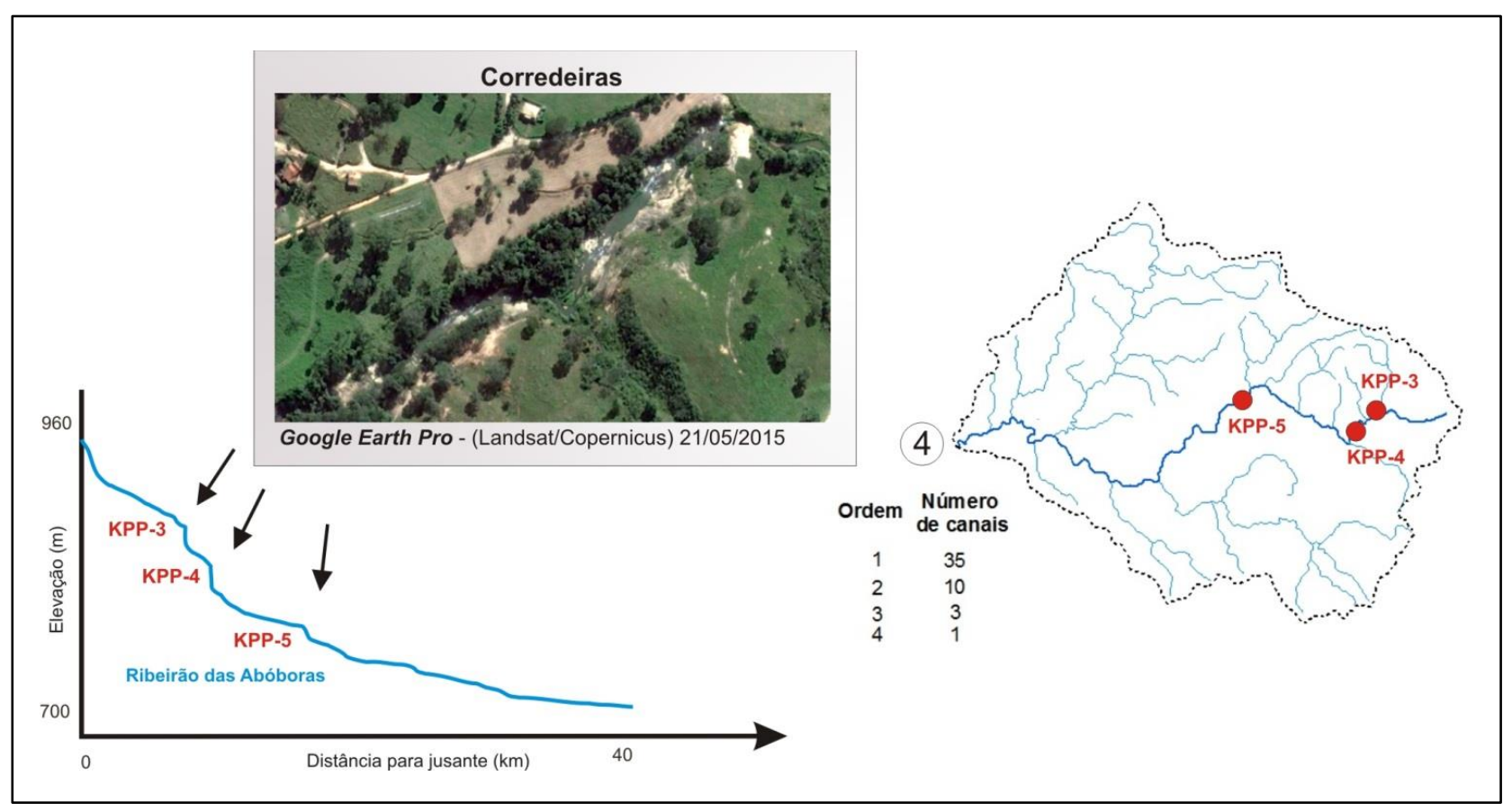

Figura 8 - Perfil longitudinal do ribeirão das Abóboras e seus respectivos knickpoints.

Fonte: Organizado pelos autores.

Dentre os quatro afluentes do rio Paraopeba, o ribeirão dos Macacos é aquele em que se registrou um único knickpoint (Figura 6). Esse ribeirão corresponde a um canal de $4^{\mathrm{a}}$ ordem de $62.677 \mathrm{~m}$ de extensão, o segundo maior comprimento dentre os demais, além de sua bacia hidrográfica ocupar área de $844 \mathrm{~km}^{2}$. A rede hidrográfica dessa bacia compreende 91 segmentos de $1^{\mathrm{a}}$ ordem, 32 de $2^{\mathrm{a}}$ ordem, 4 de $3^{\mathrm{a}}$ ordem e o próprio ribeirão dos Macacos como $4^{\mathrm{a}}$ ordem (Quadro 1). Nota-se que apesar das dimensões consideráveis dessa bacia há quantidade significativa de canais que ocupam posição de cabeceiras de drenagem, sendo a amplitude topográfica desse curso fluvial também maior (361m). O KPP-6, localizado nesta bacia, gera uma queda d'água situada no município de Esmeraldas (Figura 9). Seus parâmetros morfométricos indicam declividade máxima de $11,58^{\circ}$ em uma extensão de $68 \mathrm{~m}$, ao passo que o trecho possui uma média de $5,98^{\circ}$ ao longo de 418m (Quadro 1). A resposta morfológica no perfil longitudinal revela saliência côncava próximo 
da zona de cabeceira. Por se tratar de uma cachoeira detentora de relativo atrativo turístico, no Panoramio há registros fotográficos de pessoas que visitaram o local (Figura 9).

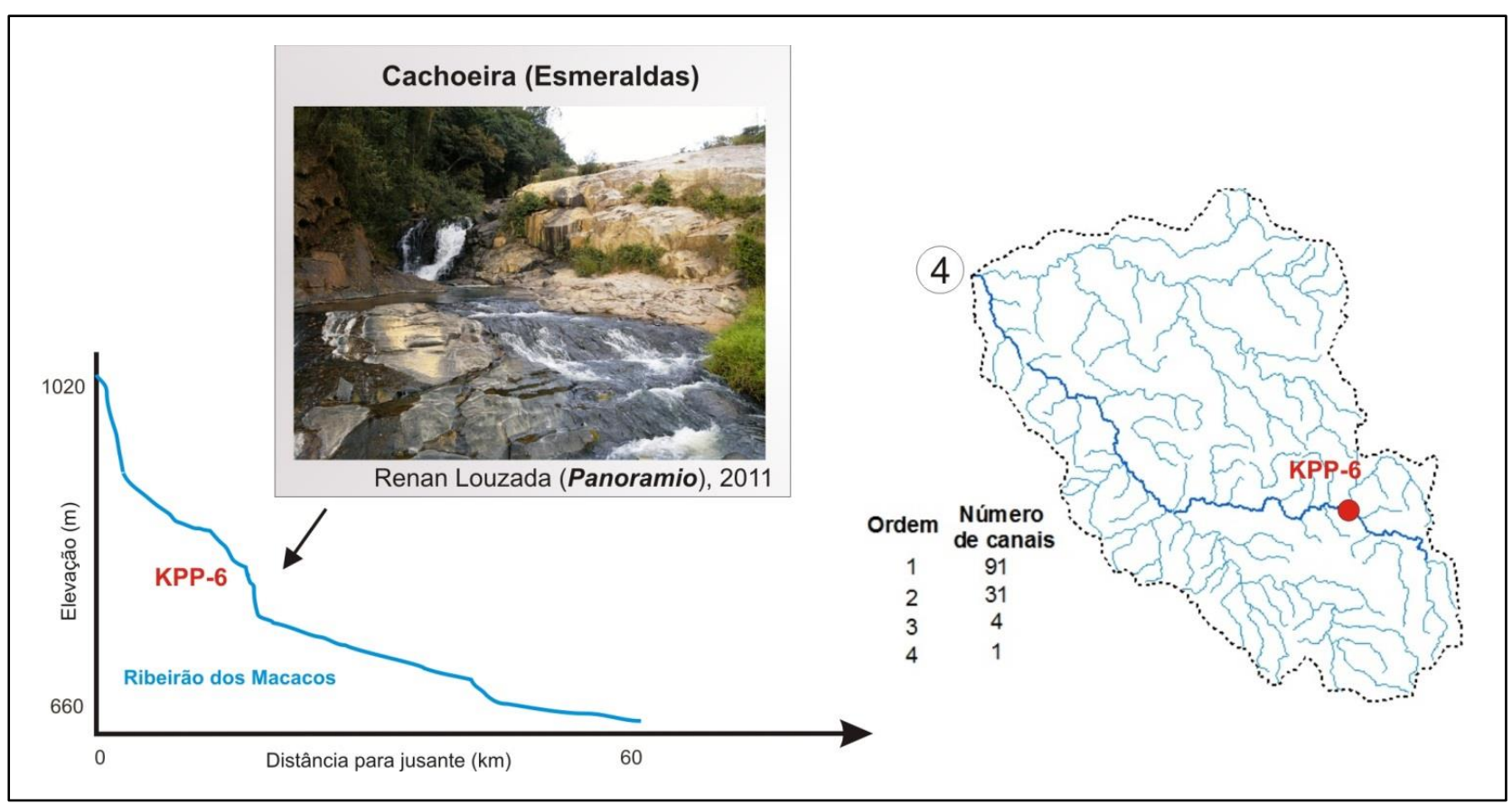

Figura 9 - Perfil longitudinal do ribeirão dos Macacos e seu respectivo knickpoint.

Fonte: Organizado pelos autores.

Por fim, em relação aos afluentes do rio Paraopeba, o ribeirão Cedro é o único que não contém rupturas abruptas na declividade em seu perfil longitudinal, além de registar maior regularidade quanto à sua concavidade morfológica (Figura 10). O ribeirão do Cedro possui $44.103 \mathrm{~m}$ de extensão e drena área de $335 \mathrm{~km}^{2}$. A amplitude altimétrica desse curso fluvial é de $346 \mathrm{~m}$, sendo que sua rede de tributários apresenta 25 segmentos de $1^{\mathrm{a}}$ ordem, 6 de $2^{\mathrm{a}}$ ordem, 2 de $3^{\mathrm{a}}$ ordem e o ribeirão do Cedro de $4^{\mathrm{a}}$ ordem (Quadro 1). Pelo gráfico do perfil longitudinal desse curso d'água notam-se pequenas irregularidades, notadamente no ribeirão das Abóboras (Figura 8). Dado o caráter mais regular deste ribeirão, imagens orbitais não são capazes de registrar claramente trechos de corredeiras, assim como não consta fotografias no Panoramio. 


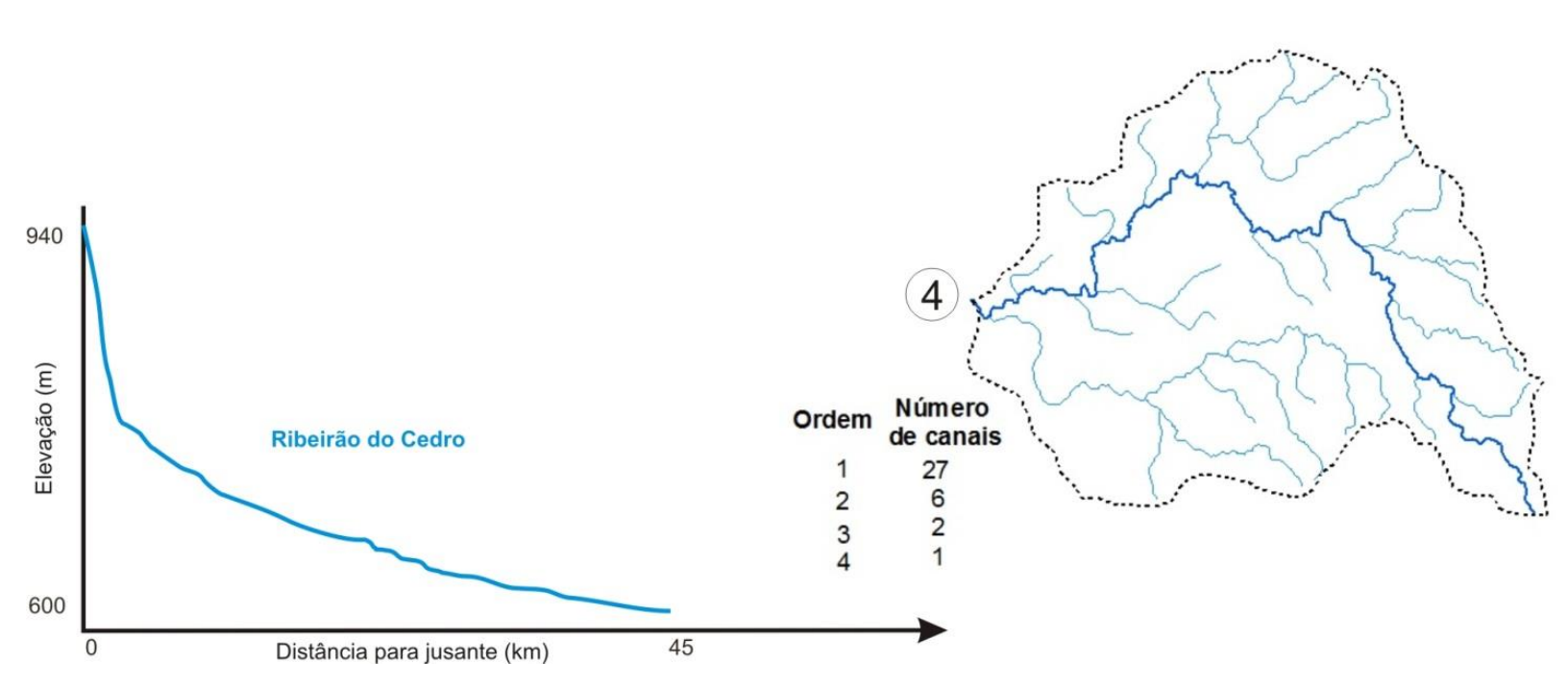

Figura 10 - Perfil longitudinal do ribeirão dos Macacos e sua respectiva bacia hidrográfica. Fonte: Organizado pelos autores.

Nos afluentes do rio das Velhas estão presentes três dos nove knickpoints reconhecidos neste trabalho. No ribeirão Onça, localizado no município de Belo Horizonte (Figura 6), é que ocorrem dois deles, os knickpoints KPV-1 e o KPV-2. Este ribeirão foi hierarquizado como de $2^{\mathrm{a}}$ ordem, embora sua bacia já se encontre muito ocupada pelo tecido urbano, o que dificulta a acurácia da hierarquização. A do ribeirão Onça possui $195 \mathrm{~km}^{2}$ e nela foram identificados 7 canais de $1^{\mathrm{a}}$ ordem.

A extensão do ribeirão Onça é de $33.861 \mathrm{~m}$ e a variação de sua amplitude altimétrica é de 265m (Quadro 1). O knickpoint KPV-1, situado na porção mediana da bacia, apresenta declividade de ruptura de até $7,81^{\circ}$ ao longo de extensão de $89 \mathrm{~m}$. Em imagens de satélite se confirma que exatamente neste knickpoint foi construída a barragem da Lagoa da Pampulha (Figura 11), inaugurada em 1938 e reinaugurada em 1958 após seu rompimento, conforme explicitado por Resck et al. (2007). O lago decorrente da construção desta barragem foi, de início, destinado ao abastecimento público, interrompido mais tarde em razão da deterioração de suas águas pela intensificação do processo de urbanização da capital, responsável pelo lançamento de resíduos em suas águas, eutrofização e assoreamento.

O KPV-2 se localiza na proximidade da confluência do ribeirão Onça com o rio das Velhas. Sua morfometria revela declividade máxima de $20,15^{\circ}$ ao longo de $27 \mathrm{~m}$ (Quadro 1). Trata-se do knickpoint que possui a ruptura mais abrupta quando comparado àquelas dos demais canais, o que justifica a ocorrência neste ribeirão da cachoeira de maior desnível altimétrico da área investigada (Figura 11), de fácil reconhecimento em imagens orbitais e em fotografias arquivadas no Panoramio. 


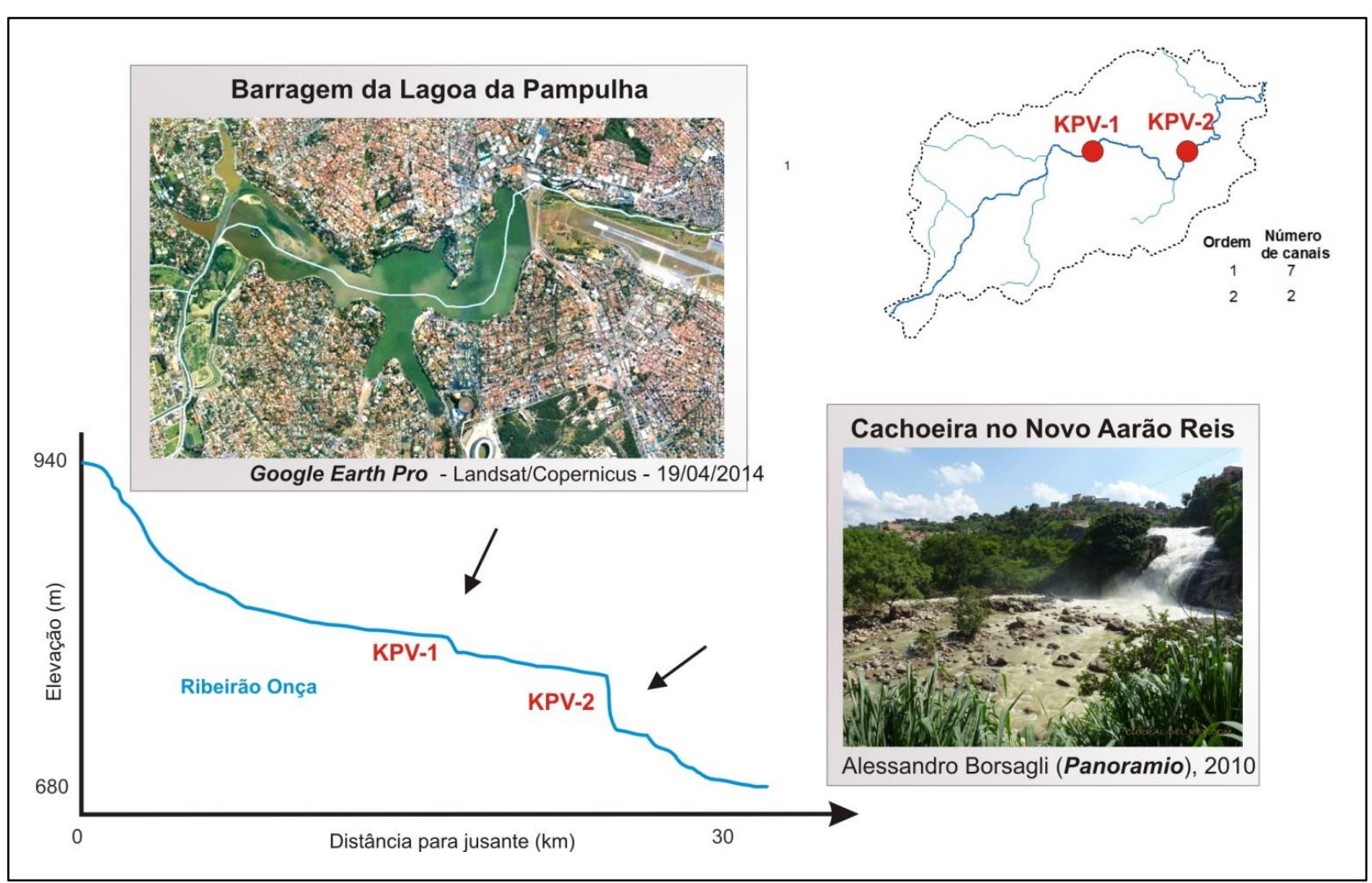

Figura 11 - Perfil longitudinal do ribeirão Onça e seus respectivos knickpoints.

Fonte: Organizado pelos autores.

Ao norte do ribeirão Onça está localizada a bacia do ribeirão da Mata, na qual ocorre o KPV-3. Uma vez localizado no médio trecho do ribeirão da Mata, próximo à rodovia MG-424 no município de Pedro Leopoldo, este knickpoint se expressa em uma pequena queda d'água cujo registro em vídeo se encontra postado no Youtube (Figura 12). O KPV-3 apresenta declividade máxima de $7,52^{\circ}$ distribuída em extensão de $105 \mathrm{~m}$. O ribeirão da Mata possui a maior extensão longitudinal quanto aos demais canais investigados, pois alcança $66.660 \mathrm{~m}$, sendo sua amplitude altimétrica $318 \mathrm{~m}$. Corresponde à $4^{\mathrm{a}}$ ordem de Strahler (1957) e a área drenada por sua bacia é de $809 \mathrm{~km}^{2}$, na qual se distribuem 94 canais de $1^{\mathrm{a}}$ ordem, 15 de $2^{\mathrm{a}}$ ordem e 3 de $3^{\mathrm{a}}$ ordem. A morfologia de seu perfil longitudinal apresenta ruptura abrupta em seu médio curso, o KPV-3 (Figura 12).

Nas bacias dos rios Jequitibá e Tabocas não foram reconhecidos knickpoints ao longo de seus perfis longitudinais, como demonstra a Figura 13. De morfologia relativamente mais regular quando comparado ao ribeirão do Cedro, o ribeirão das tabocas corresponde a uma bacia alongada de $3^{\mathrm{a}}$ ordem e ocupa área de $217 \mathrm{~km}^{2}$. Possui 27 canais de $1^{\mathrm{a}}$ ordem e 4 de $2^{\mathrm{a}}$ ordem, sendo a extensão de seu principal curso fluvial de $48.473 \mathrm{~m}$, ao longo de variação altimétrica de $351 \mathrm{~m}$ (Quadro 1). Quanto ao ribeirão Jequitibá, este corresponde a canal de $4^{\mathrm{a}}$ ordem, cuja bacia ocupa área de $575 \mathrm{~km}^{2}$, a qual contém 41 canais de $1^{\mathrm{a}}$ ordem, 8 de $2^{\mathrm{a}}$ e 3 de $3^{\mathrm{a}}$ ordem. $\mathrm{O}$ comprimento deste ribeirão é de $58.879 \mathrm{~m}$ e sua amplitude altimétrica é de $327 \mathrm{~m}$. Nem imagens orbitais, tampouco 
fotografias no Panoramio, revelaram trechos de corredeiras ou mesmo cachoeiras ao longo de seu trajeto.

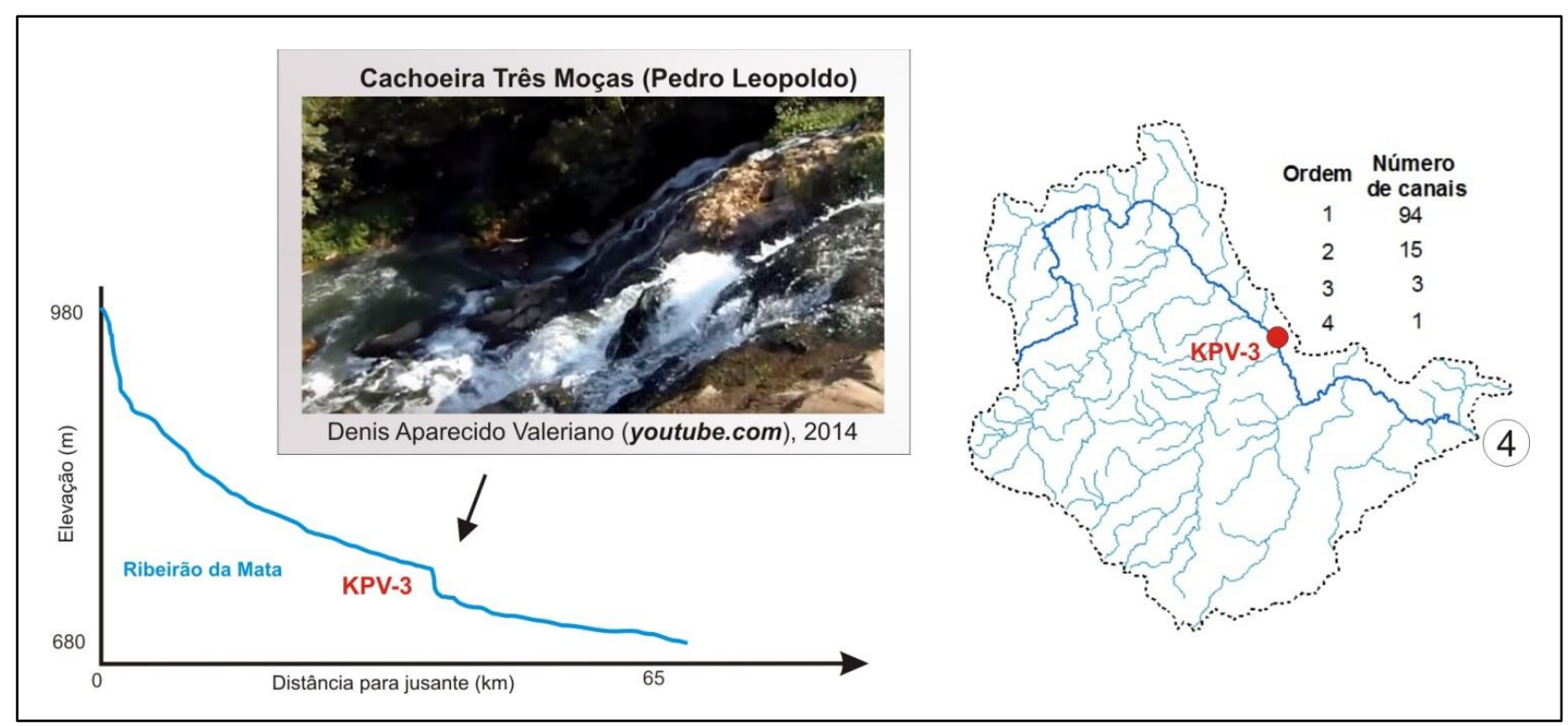

Figura 12 - Perfil longitudinal do ribeirão da Mata e seu respectivo knickpoint.

Fonte: Organizado pelos autores.

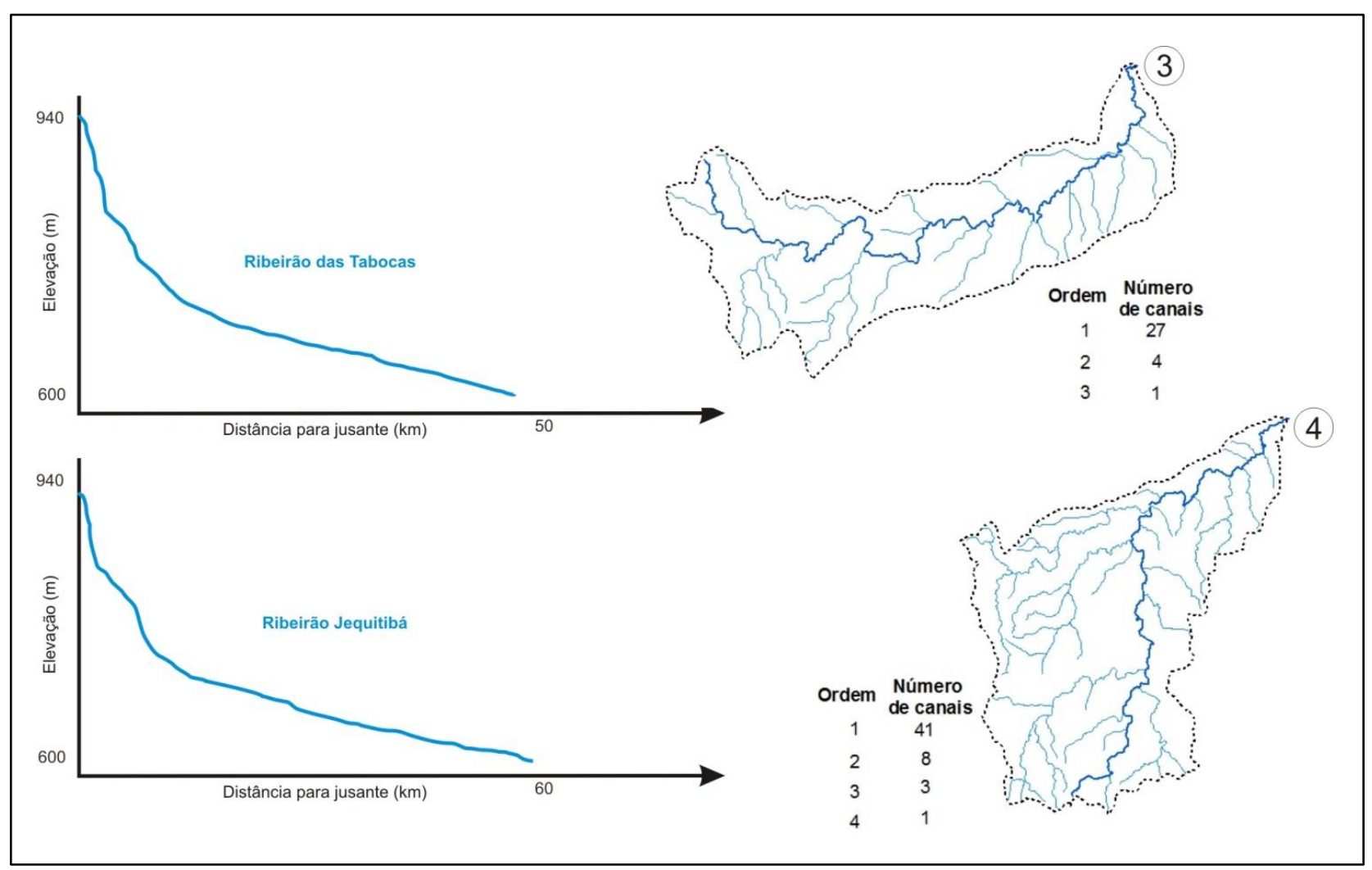

Figura 13 - Perfis longitudinais dos ribeirões das Tabocas e Jequitibá e suas respectivas bacias hidrográficas.

Fonte: Organizado pelos autores. 


\section{CONSIDERAÇÕES FINAIS}

Este trabalho confirma a viabilidade do emprego de recursos geotecnológicos no reconhecimento e caracterização visual e quantitativa de significativas rupturas de declives presentes em canais fluviais que integram o divisor hidrográfico centro-sul das bacias dos rios das Velhas e Paraopeba. Para tanto, foram efetivadas a análise de modelo digital de elevação (MDE) SRTM do Projeto Topodata (INPE, 2008) e o seu processamento em ambiente ArcGIS 10.1. Uma vez reconhecidos os aspectos geométricos das principais rupturas presentes nos canais fluviais, a etapa seguinte consistiu em uma primeira aproximação dos aspectos paisagísticos desses knickpoints, o que revelou a ocorrência de quedas d'água com desnível médio de 10m, como também corredeiras. É notória, ainda, a utilização de alguns desses knikcpoints para a construção de barragens destinadas ao abastecimento hídrico. O desenvolvimento deste trabalho comprova que a partir do MDE é possível a identificação e caracterização geométrica de knickpoints, ao passo que imagens orbitais disponibilizadas no Google Earth Pro, fotografias de usuários postadas no Panoramio e registros em vídeo no Youtube se configuram instrumentos de gabinete complementares para o reconhecimento visual dessas rupturas. Tratam-se, portanto, de procedimentos passíveis de execução em gabinete de marcada relevância no planejamento e execução de posteriores trabalhos em campo.

\section{REFERÊNCIAS}

CARLSTON, C.W. Longitudinal slope characteristics of rivers of the Midcontinent and the Atlantic East Gulf Slopes. International Association of Scientific Hydrology Bulletin, v.14, n.4. p.21-31. 1969; DOI:10.1080/02626666909493751.

CHARLTON, R.O. Fundamentals of Fluvial Geomorphology. Nova York, ed. Routledge, 275p. 2008.

CORSEUIL, C.W. Técnicas de geoprocessamento e de análise de multicritérios na adequação de uso das terras. Tese, Faculdade de Ciências Agronômicas da UNESP, Botucatu, SP, Área de Concentração em Energia na Agricultura. 101f. 2006.

DAVIS, W.M. The geographical cycle. The Geographical Journal. v.14, n. 5, p. 481-504, 1899.

HARTVICH, F. Analysis of the longitudinal profiles of selected rivers in the Šumava Mts., Southwest Bohemia. Miscellanea Geographica 11/2005, p.13-30, 2005. 
HASUI, Y. Quadro geral da evolução pré-ordoviciana: a conexão Brasil-África. In: HASUI, Y.; CARNEIRO, C.D.R.; ALMEIDA, F.F.M.; BARTORELli, A. Geologia do Brasil. São Paulo: Editora Beca, 2012. Cap. 8, p.123-130.

IBGE - INSITUTO BRASILEIRO DE GEOGRAFIA E ESTATÍSTICA. Base de dados vetoriais para rede de drenagem (escala 1:100.000), limites federativos (1.1.000.000), 2008.

INPE - INSTITUTO NACIONAL DE PESQUISAS ESPACIAIS. Projeto TOPODATA: banco de dados geomorfométricos do Brasil. São José dos Campos, 2008.

FERREIRA, M.V.; TINÓS, T.M.; PINTON, L.G.; CUNHA, C.M.L. A dissecação horizontal como parâmetro morfométricos para avaliação do relevo: uma proposta técnica digital automática. Revista Brasileira de Geomorfologia, São Paulo, v.15, n.4, p.585-600, 2014.

GRIFFITHS, J.S.; SMITH, M.J.; PARON, P. Introduction to Applied Geomorphological Mapping. Cap.1, p. 3-11. In SMITH, M.J.;PARON, P.; GRIFFITHS, J.S. Geomorphological mapping: methods and applications. Oxford: Elsevier. f.661. Developments in Earth Surface Processes, Volume 15, Elsevier, 2011.

RÃDOANE, M.; RÃDOANE, N. DUMITRIU, D. Geomorphological evolution of longitudinal river profiles in the Carpathians. Geomorphology, n.50, p. 293-306. 2003.

RESCK, R.P.; BEZERRA NETO, J.F.; COELHO, R.M.P. Nova batimetria e avaliação de parâmetros morfométricos da Lagoa da Pampulha (Belo Horizonte, Brasil). Geografias, v.3, n.2, p.17-23, 2007.

SANTOS, S.P. Morfometria, compartimentação e hidrodinâmica de um reservatório periurbano tropical: prognósticos sobre o tempo de vida útil do reservatório de Vargem das Flores, Minas Gerais - Brasil. Dissertação. Instituto de Ciências Biológica, Universidade Federal de Minas Gerais. Ecologia, conservação e manejo da vida silvestre. 131 f. 2012.

SCHUMM, S.A.; LICHTY, R.W. Time, space and causality in Geomorphology. American Journal of Science 263: p.110-119, 1965.

SELANDER, J. Influences on river morphology in a sediment-dominated system. Chapter Four, p.1-13, Mobogenie.Com/Download-Software, 2004.

SKLAR, L.; DIETRICH, W.E. 1998. River longitudinal profiles and bedrock incision models: stream power and the influence of sediment supply. See Tinkler \& Wohl p, 237-260, 1998.

STRAHLER, A.N. Quantitative Analysis of Watershed Geomorphology. Transactions, American Geophysical Union, v.38, n.6, p. 913-920, 1957. 